\title{
LICENCIAMENTO AMBIENTAL DO PORTO CENTRAL DE PRESIDENTE KENNEDY - UM ESTUDO DE CASO
}

\section{STÉPHANIE LÃ FERRARI 1, MARCUS VINÍCIUS COUTINHO GOMES ${ }^{2}$.}

1 Pós-Graduanda em Direito Ambiental e Urbanístico pela Damásio Educacional e Graduada em Direito pela Faculdade de Direito de Cachoeiro de Itapemirim (FDCI), Cachoeiro de Itapemirim - ES, Brasil. ferraristephanie96@gmail.com.

2 Doutor em Sociologia Política pela Universidade Estadual do Norte Fluminense Darcy Ribeiro (UENF), Mestre e Graduado em Direito pelo Centro Universitário Fluminense (UNIFLU) e Prof. de Direito Ambiental da Faculdade de Direito de Cachoeiro de Itapemirim (FDCI), Cachoeiro de Itapemirim - ES, Brasil.marcus.gomes4@gmail.com.

\section{RESUMO}

Este trabalho teve como objetivo analisar o processo de licenciamento ambiental do Porto Central de Presidente Kennedy, localizado ao sul do Estado de Espírito Santo, Brasil. O Porto Central é uma Joint Venture composta pelo Porto de Roterdã (Holanda) e pela TPK Logística S.A. (Brasil). Utilizou-se como metodologia o estudo de caso, com base em levantamento de dados e a análise de legislações específicas, revistas e doutrinas especializadas no âmbito do direito ambiental. Também foi realizado um levantamento sobre a história do complexo portuário no Brasil. Verificou-se que o licenciamento ambiental é um procedimento administrativo criado pela Política Nacional do Meio Ambiente, regulamentado pela Resolução n. 237/1997 do Conselho Nacional do Meio Ambiente e que compete ao IBAMA, órgão federal competente, o licenciamento ambiental do Porto Central. Constatou-se que o processo de licenciamento ambiental do Porto Central teve início no ano de 2011 e passou por duas fases do licenciamento. No decorrer do EIA/RIMA, houve a necessidade de ajustes para favorecer a comunidade pesqueira local, no qual foi alterado o local de descarte marinho e elaborado o Plano de Compensação de Atividade Pesqueira. Atualmente, possui a licença de instalação. O porto obterá, em meados do ano 2024, a última licença, que será a de operação. Enfatiza-se que, em todas as fases do licenciamento, é necessário o monitoramento dos impactos, a fim de minimizar os danos provocados ao meio ambiente, aliando crescimento econômico e preservação ambiental.

Palavras-chave: Complexo Portuário; Direito Ambiental; Licença Ambiental; Meio Ambiente. 


\title{
ENVIRONMENTAL LICENSING OF THE CENTRAL PORT OF PRESIDENT KENNEDY - A CASE STUDY
}

\begin{abstract}
This work aimed to analyze the environmental licensing process of the Central Port of Presidente Kennedy, located in the south of the State of Espírito Santo, Brazil. Porto Central is a Joint Venture composed of the Port of Rotterdam (Netherlands) and TPK Logística S.A. (Brazil). The methodology used was a case study, based on data collection and analysis of specific laws, magazines and specialized doctrines within the scope of environmental law. A survey was also carried out on the history of the port complex in Brazil. It was found that environmental licensing is an administrative procedure created by the National Environment Policy, regulated by Resolution No. 237/1997 of the National Environment Council and the IBAMA, the competent federal body, is responsible for the environmental licensing of Porto Central. It was found that the environmental licensing process in Porto Central began in 2011 and went through two phases of licensing. During the EIA / RIMA, adjustments were needed to favor the local fishing community, in which the marine disposal site was changed and the Fishing Activity Compensation Plan was prepared. Currently, it has the installation license. The port will obtain, in the middle of the year 2024, the last license, which will be the operation. It is emphasized that, at all stages of licensing, it is necessary to monitor impacts, in order to minimize damage to the environment, combining economic growth and environmental preservation.
\end{abstract}

Keywords: Port Complex; Environmental Law; Environmental License; Environment.

\section{INTRODUÇÃO}

Devido às externalidades negativas causadas ao meio ambiente por empreendimentos e atividades potencialmente poluidoras que utilizam de recursos naturais, a Política Nacional do Meio Ambiente criou um procedimento administrativo, denominado licenciamento ambiental, visando conciliar a preservação do meio ambiente, o crescimento econômico e a melhoria da qualidade de vida da sociedade, sendo estes os três pilares do desenvolvimento sustentável.

O licenciamento ambiental é uma obrigação legal prévia à instalação de empreendimentos ou atividades potencialmente poluidoras ou degradadoras do meio ambiente e é composto por, no mínimo, três etapas: licença prévia, licença de instalação 
e a licença de operação. O licenciamento ambiental de portos é um procedimento indispensável, tendo em vista o tamanho do empreendimento e por ser uma atividade causadora de grande degradação ambiental.

O objetivo do trabalho foi analisar o processo de licenciamento ambiental do Porto Central, localizado no município de Presidente Kennedy, Espírito Santo. Para tanto, realizaram-se uma visita de campo e consultas a documentos e em legislações que regem o licenciamento ambiental de Portos. Para contextualização do tema do trabalho, realizou-se também uma pesquisa sobre a história do complexo portuário no Brasil, principalmente o do Espírito Santo.

O licenciamento ambiental de portos é pouco conhecido no cenário brasileiro, de modo que o panorama trazido por este trabalho poderá servir de estudo sobre os detalhes deste procedimento. É imperativo conhecer o processo de licenciamento ambiental do Porto Central, além de ser um exercício do direito ambiental, possibilita a aproximação ou o diálogo com outras áreas do direito, tais como: o direito portuário, o direito aduaneiro, o direito marítimo, o direito internacional, entre outros.

\section{2 ÁREA DE ESTUDO}

O Porto Central é um projeto internacional de complexo industrial portuário privado que está sendo instalado no município capixaba de Presidente Kennedy, centro sudoeste da costa brasileira (Ilustração $1 \mathrm{~A}$ ), próximo da fronteira do estado do Espírito Santo com o Rio de Janeiro. Na Ilustração 1 B, é apresentado o leiaute do projeto a ser implementado no município de Presidente Kennedy e, no Quadro 1, suas características. 
Ilustração 1 - Projeto do Porto Central: A. Localização e acesso marítimo; B. Leiaute do projeto
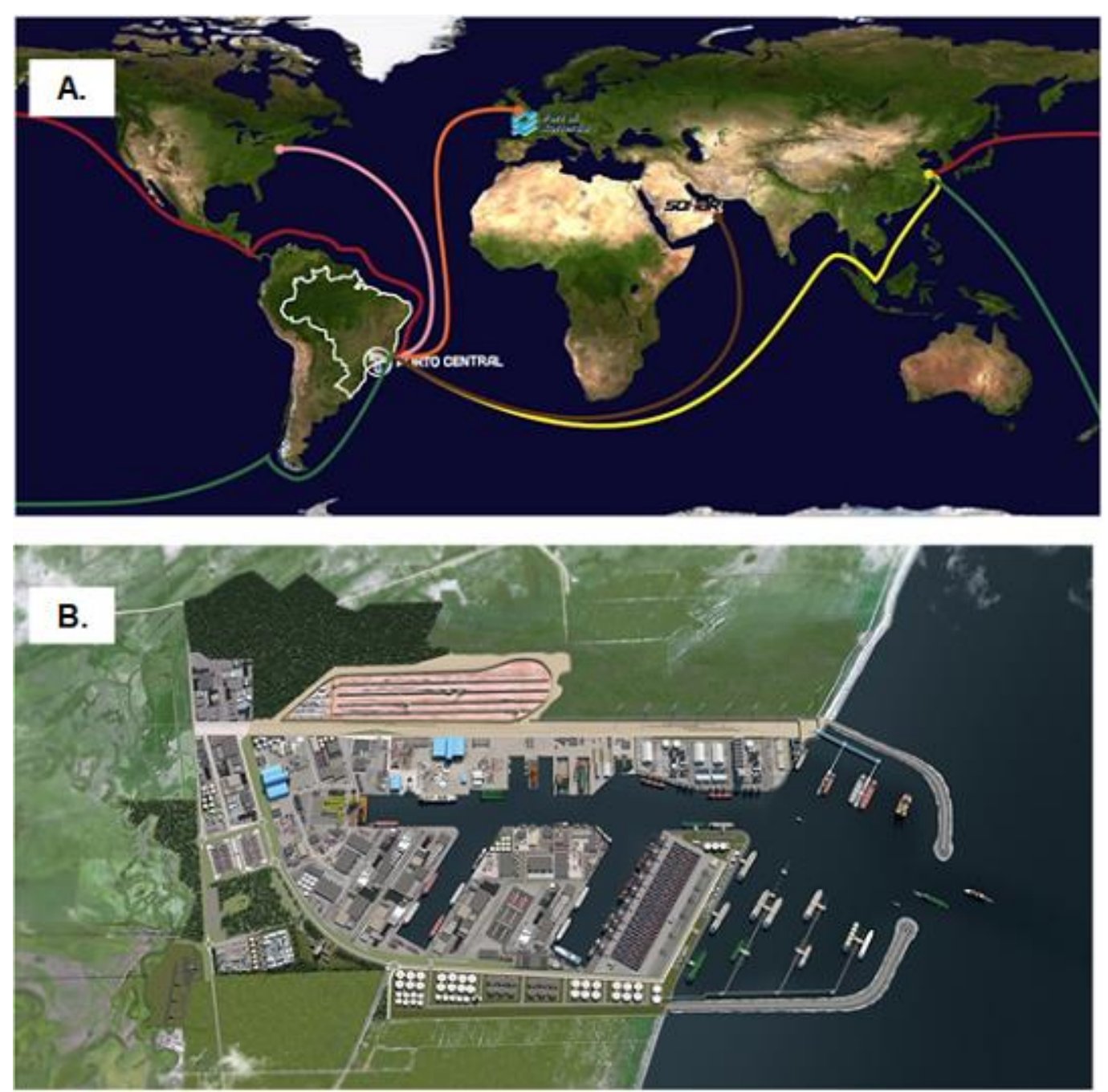

Fonte: Porto Central (2019), adaptado pelos autores

Quadro 1 - Dados do projeto do Porto Central

\begin{tabular}{|l|c|}
\hline \multicolumn{1}{|c|}{ VARIÁVEIS } & MEDIDAS \\
\hline Área total & $2.000 \mathrm{ha}$ \\
\hline Área verde & $200 \mathrm{ha}$ \\
\hline Profundidade & $10 \mathrm{a} 25 \mathrm{~m}$ \\
\hline Largura do canal de acesso & $300 \mathrm{~m}$ \\
\hline Largura do canal interno & $360 \mathrm{~m}$ \\
\hline Berços e Píeres & 53 berços e $10.000 \mathrm{~m}$ de cais \\
\hline Capacidade de navios & 400.000 DWT(Valemax) e 320.000 DWT \\
(Petroleiros)
\end{tabular}

Fonte: Elaborado pelos autores com base em Porto Central (2019). 
O projeto teve início em 29 de abril de 2014, por uma Joint Venture composta pelo Porto de Roterdã (Holanda) e pela TPK Logística S.A. (Brasil) (PORTO CENTRAL, 2019). O Porto de Roterdã é uma empresa com mais de 600 anos de experiência em gestão e desenvolvimento de infraestrutura portuária de classe mundial em Roterdã e, internacionalmente, com a sua Rede Global de Portos. Seus principais acionistas são o Município de Roterdã (aprox. 70\%) e o Governo Holandês (aprox. 30\%) (PORTO CENTRAL, 2019). O Porto de Roterdã é considerado o maior complexo industrial portuário da Europa e o oitavo maior do Mundo. Possui 12.713 ha de extensão e, em 2017, movimentou 467,4 milhões de toneladas (PORTOFROTTERDAM, 2018). A TPK Logística S.A. é uma empresa brasileira que atua nas áreas de operação portuária, mineração, construção civil, logística, indústria offshore e energia. A sua principal acionista é a Polimix, considerada uma das maiores produtoras de concreto do Brasil. A Polimix possui 190 Usinas de Concreto, produz mais de 8 milhões de $\mathrm{m}^{3} /$ ano e está presente em 21 Estados brasileiros e 6 outros países (PORTO CENTRAL, 2019).

O projeto do Porto Central está sendo desenvolvido sob o conceito de cluster, no modelo de condomínio portuário, no qual os empreendedores serão responsáveis pela infraestrutura portuária e as áreas para a implantação de indústrias e terminais serão arrendadas. De acordo com Lam e Zhang (2011) e Viederyté e Diksaité (2014), a aglomeração de empresas e indústrias do setor marítimo ou de setores correlatos (clusters marítimos) possibilitam diversas vantagens competitivas, tais como: o aumento de produtividade; a complementaridade entre as empresas; a oportunidades para novos negócios e redução de barreiras no mercado; acesso a bens públicos, a insumos e a informação especializada, entre outras.

O participante majoritário do projeto será a TPK Logística (aprox. 70\% de participação), seguido pelo Porto de Roterdã, que ficará com quase 30\% de participação e pelo governo do Espírito Santo (aprox. 1\%) (PORTO CENTRAL, 2019). Em relação aos clusters estão previstos: Óleo e Gás (incluindo GNL); Geração de energia; Agronegócio (como soja, milho e fertilizantes); Carga geral (como produtos siderúrgicos, granito e mármore, carros e equipamentos); Contêineres; Minerais (como minério de ferro); Indústrias Offshore (como base de apoio e estaleiros navais) (PORTO CENTRAL, 2019). 
Segundo Porto Central (2019), a escolha da área do município de Presidente Kennedy para sediar o Porto Central se deu a vários pontos positivos como: baixa densidade populacional, não possuir fragmentos de Mata Atlântica, possuir área plana, e a localidade está próximo a vias importantes como a BR 101, o Estado se apresenta amigável a empreendimentos e dispõe de excelente incentivo ao Programa de Incentivo ao Investimento no Estado do Espírito Santo (INVEST-ES, 2019), e o local já havia sido identificado pela Agência Nacional de Transportes Aquaviários (ANTAQ) como propício para a construção de porto.

De fato, o município de Presidente Kennedy apresenta poucos habitantes quando comparado a outros municípios como Marataízes-ES. De acordo com os dados do Instituto Brasileiro de Geografia e Estatística (IBGE, 2019?), a população do município de Presidente Kennedy é de 11.488 pessoas, o que representa 30,14\% da população de Marataízes. A maior parte da população de Kennedy vive em áreas rurais (cerca de 66\%). As manchas urbanas do município são apenas cinco, a saber: cidade de Presidente Kennedy, São Paulo, Jaqueira, Santo Eduardo, Praia das Neves e Praia de Marobá (Ilustração 2).

De acordo com os dados do IBGE (2019?), o Produto Interno Bruto (PIB) per capita de Presidente Kennedy é de R\$292.397,08 (dados de 2017) e o Índice de Desenvolvimento Humano Municipal (IDHM) é de 0,657 (dados de 2010). O PIB é um indicador econômico que representa a soma, em valores monetários, de todos os bens e serviços produzidos, consumidos e investidos, numa determinada região em determinado período. Quando comparado aos outros municípios brasileiros, Presidente Kennedy se destaca como sendo o município que apresenta o maior PIB per capita da Microrregião Sul e do Estado e o $17^{\circ}$ maior PIB per capita do País (IBGE, 2019?). O maior percentual das receitas, porém, é oriundo de fontes externas à sua arrecadação que alcança um patamar de 64,7\% (IBGE, 2019?). As principais fontes são royalties do Petróleo e os recursos do Fundo Nacional de Desenvolvimento da Educação (FNDE) (PMK, 2019).

O IDH do município de Presidente Kennedy $(0,667)$ é caracterizado como de médio desenvolvimento humano, ou seja, IDH de 0,500-0,799, conforme a classificação da Convenção da Organização das Nações Unidas (PNUD, 2019?). Este índice, que varia de 0 a 1 , sinaliza a qualidade de vida humana, considerando a expectativa de vida 
ao nascer, a educação e o PIB per capita.

Ilustração 2 - Mapa dos limites administrativos do município de Presidente KennedyES e localização da futura instalação do Porto Central

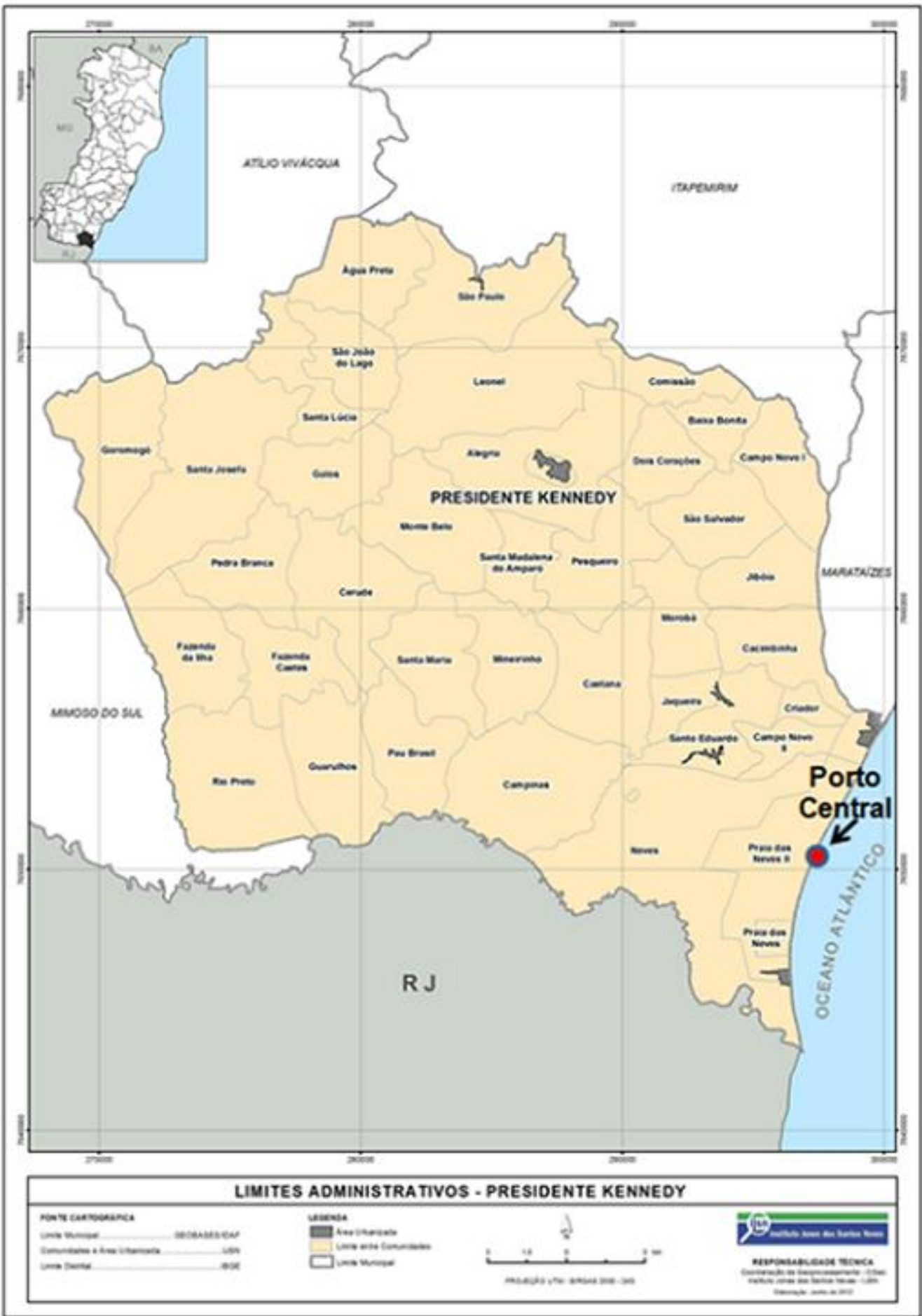

Fonte: Instituto Jones dos Santos Neves (2019?), adaptado pelos autores. 
Em relação ao uso e ocupação solo (Ilustração 3), verifica-se que a maior parte da extensão territorial de Presidente Kennedy é destinada às pastagens e ao plantio de culturas como mandioca, cana-de-açúcar e abacaxi, dentre outras (IJSN, 2019?). A presença de remanescentes florestais de Mata Atlântica no município também pode ser notada, contrariando um dos motivos da escolha do município que é de não possuir fragmentos de Mata Atlântica (PORTO CENTRAL, 2019). A Mata Atlântica é uma das maiores florestas tropicais do planeta e abriga uma biota extremamente diversificada. De acordo com os dados do SOS MATA ATLÂNTICA (2019?), o município de Presidente Kennedy possuí 4.742 ha de remanescentes florestais de Mata Atlântica, o que representa $8,12 \%$ da extensão territorial do município.

Constata-se também, na Ilustração 3, que o Porto Central ficará localizado numa área de restinga, entre a Praia das Neves e a Praia de Marobá. Ressalta-se que tal ecossistema (restinga) é típico do domínio Mata Atlântica e compreende um conjunto geomorfológico formado pela deposição de sedimentos arenosos de origem marinha e flúvio-marinha, com diversas formações como barras, esporões e planícies ao longo do litoral do Brasil, apresentando, de acordo com o estágio sucessional, estrato herbáceo, arbustivo e arbóreo (THOMAZI et al., 2013).

De acordo com a Lei $\mathrm{n}^{\circ} 12.651 / 2012$, as restingas são consideradas Áreas de Proteção Permanente (APP), como fixadoras de dunas ou estabilizadoras de mangues (BRASIL, 2012, on-line) e somente poderá ocorrer intervenção ou supressão nesse tipo de vegetação em caso de hipótese de utilidade pública, de interesse social ou de baixo impacto ambiental, como previsto nessa referida Lei. No caso do licenciamento ambiental do Porto Central, o pedido de intervenção e supressão da restinga ocorreu concomitantemente ao processo e enquadrou-se como uma hipótese de utilidade pública conforme Análise da solicitação de Licença de Instalação do empreendimento Porto Central (IBAMA, 2019). 
Ilustração 3 - Mapa de uso e ocupação da terra do município de Presidente

Kennedy-ES e localização da futura instalação do Porto Central

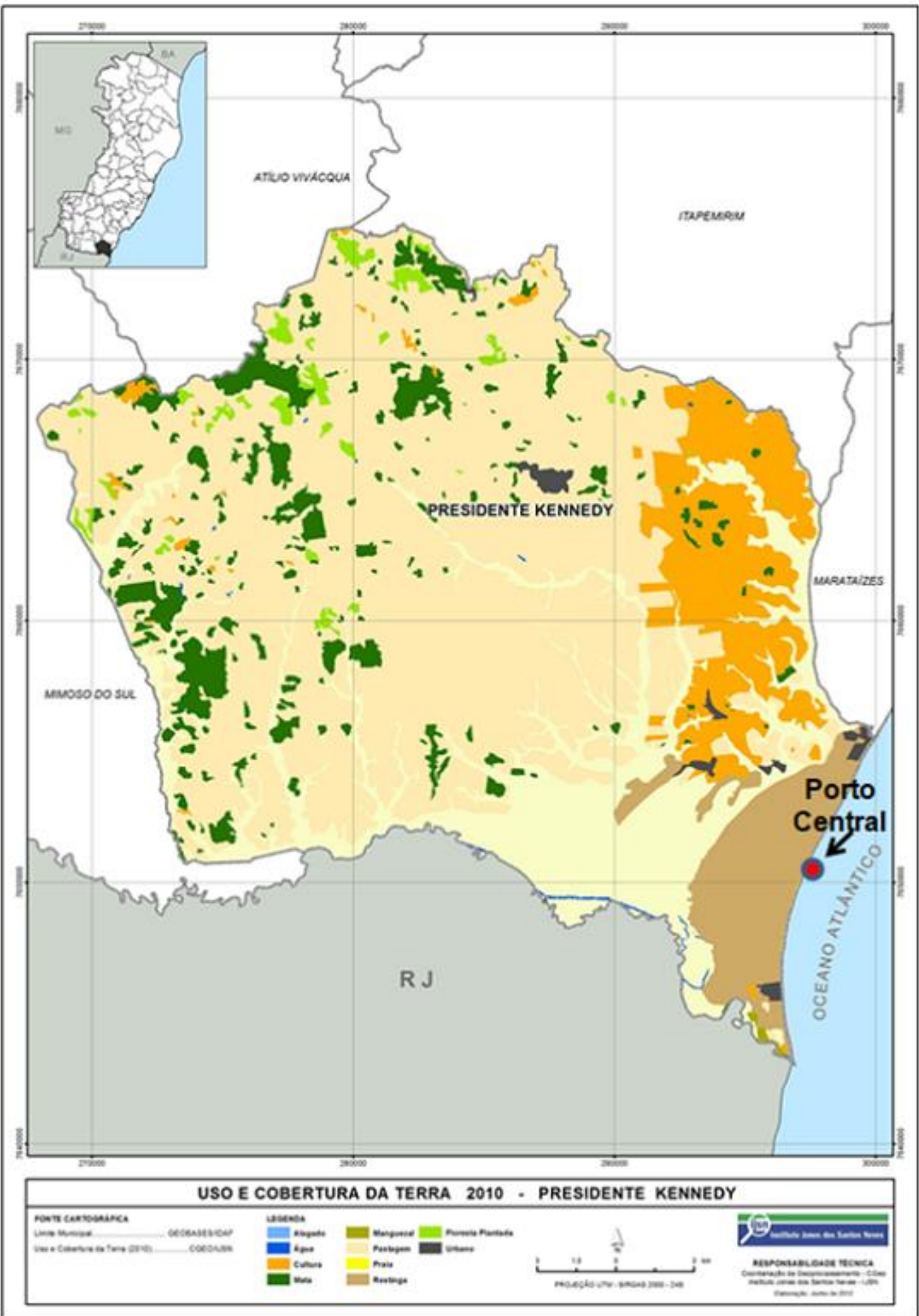

Fonte: Instituto Jones dos Santos Neves (2019b), adaptado pelos autores 


\section{METODOLOGIA}

Para a realização deste trabalho, utilizou-se como método o estudo de caso, metodologia amplamente empregada na área das ciências sociais (GIL, 2010), que consiste no estudo amplo e profundo de um determinado objeto. Após a definição da unidade-caso (o licenciamento ambiental do Porto Central), determinaram-se as técnicas de coleta e a elaboração do documento que trata das decisões relevantes tomadas ao longo da pesquisa.

A coleta de dados foi realizada com base na consulta a fontes documentais do Porto Central, da Agência Nacional de Transportes Aquaviários (ANTAQ) e do Instituto Brasileiro do Meio Ambiente e dos Recursos Naturais Renováveis (IBAMA), e a análise dos dados foi feita mediante as legislações específicas, revistas e doutrinas especializadas no âmbito do direito ambiental. Foi também realizada uma visita de campo na área de estudo, no dia 13 de julho de 2019, visando complementar as informações obtidas pela análise documental e bibliográfica.

Nas seções posteriores, foram realizadas digressões de aprofundamento advindos do protocolo delineado, buscando expor e problematizar as questões mais amplas da pesquisa e traçar o panorama atual do processo de licenciamento ambiental do Porto Central de Presidente Kennedy-ES.

\section{COMPLEXO PORTUÁRIO BRASILEIRO E UM OLHAR PARA O ESPÍRITO SANTO}

Os portos são instalações localizadas à beira de oceano, mar, lago ou rio, abrigadas de ondas e correntes, destinadas ao atracamento de barcos e navios, com pessoal, serviços e instalações necessárias para o carregamento e descarregamento de carga e movimento de pessoas e carga (GALVÃO, ROBLES, GUERISE, 2013). Eles têm ganhado cada vez mais expressão na economia mundial, assumindo papel importante na cadeia logística de várias empresas, desde a coleta da mercadoria no exportador até sua entrega no destino final. Quando estão localizados à beira de um oceano ou de um mar, eles são chamados de portos marítimos, quando à beira de um rio ou estuário, de portos fluviais e, quando destinado à recreação, são geralmente chamados de marinas (GALVÃO, ROBLES, GUERISE, 2013). 
Pode-se dizer que o início das operações de transporte de mercadorias e de pessoas ocorridas em portos no Brasil se deu a partir do dia 22 de abril de 1500, com a chegada das 13 embarcações comandadas por Pedro Alves Cabral. De lá para cá, muitas coisas aconteceram no processo evolutivo do planejamento e funcionamento de portos até a entrada em vigor da lei de modernização portuária. No Quadro 2, são apresentados os principais eventos históricos ocorridos.

Quadro 2 - Levantamento histórico da trajetória dos portos no Brasil

\begin{tabular}{|c|c|}
\hline ANO & EVENTO \\
\hline 1532 & $\begin{array}{l}\text { Criação das Capitanias Hereditárias e surgimento dos primeiros núcleos } \\
\text { portuários. }\end{array}$ \\
\hline 1808 & $\begin{array}{l}\text { Abertura dos portos brasileiros às nações amigas de Portugal. O Brasil } \\
\text { começa a se inserir no comércio internacional. }\end{array}$ \\
\hline 1822 & $\begin{array}{l}\text { Independência do Brasil. Os portos passaram a ser de responsabilidade da } \\
\text { Intendência dos Arsenais da Marinha, dentro do Ministério da Marinha. }\end{array}$ \\
\hline 1845 & Criação da Capitania dos Portos. \\
\hline 1873 & $\begin{array}{l}\text { O Ministério da Agricultura, Comércio e Obras Públicas passa a ser } \\
\text { responsável pelo policiamento e melhoramento dos portos. }\end{array}$ \\
\hline 1975 & Criação da PORTOBRÁS - Empresa Estatal de Portos do Brasil. \\
\hline 1990 & Extinção da PORTOBRÁS - Empresa Estatal de Portos do Brasil. \\
\hline 1993 & $\begin{array}{l}\text { Aprovação da Lei de Modernização Portuária (Lei } \mathrm{n}^{\circ} \text { 8.630, de } 25 \text { de } \\
\text { fevereiro de 1993). }\end{array}$ \\
\hline 2001 & Criação da ANTAQ (Lei No 10.233, de 5 de Junho de 2001). \\
\hline 2012 & $\begin{array}{l}\text { Revogação da Lei de Modernização Portuária (Lei no 8.630/1993) e proposta } \\
\left.\text { de uma nova regulamentação para os portos (Lei n }{ }^{\circ} 12.815 / 2013\right) \text {. }\end{array}$ \\
\hline
\end{tabular}

Fonte: Elaborado pelos autores com base em Barros (2013); Galvão, Robles, Guerise (2013); Brasil (1993) e Brasil (2013).

Atualmente, no Brasil, a exploração dos portos e instalações portuárias e as atividades desempenhadas pelos operadores portuários são atribuídas a União ou ao setor privado, por meio de delegação pública ou pela concessionária do porto 
organizado, conforme disposto na Lei $\mathrm{n}^{\circ}$ 12.815/2013 (BRASIL, 2013, on-line). As principais instalações portuárias brasileiras são: Porto Organizado, Terminal de Uso Privado, Estação de Transbordo de Cargas, Instalação Portuária de Registro e Instalação Portuária de Turismo. As duas primeiras são consideradas as mais importantes no litoral brasileiro (Ilustração 4). Para os fins da Lei ${ }^{\circ} 12.815 / 2013$, vide art. $2^{\circ}$, incisos I e IV, consideram-se porto organizado e terminal de uso privado:

I - porto organizado: bem público construído e aparelhado para atender a necessidades de navegação, de movimentação de passageiros ou de movimentação e armazenagem de mercadorias, e cujo tráfego e operações portuárias estejam sob jurisdição de autoridade portuária;

(...)

IV - terminal de uso privado: instalação portuária explorada mediante autorização e localizada fora da área do porto organizado; (BRASIL, 2013, on-line).

Ilustração 4 - Atuais instalações portuárias brasileiras

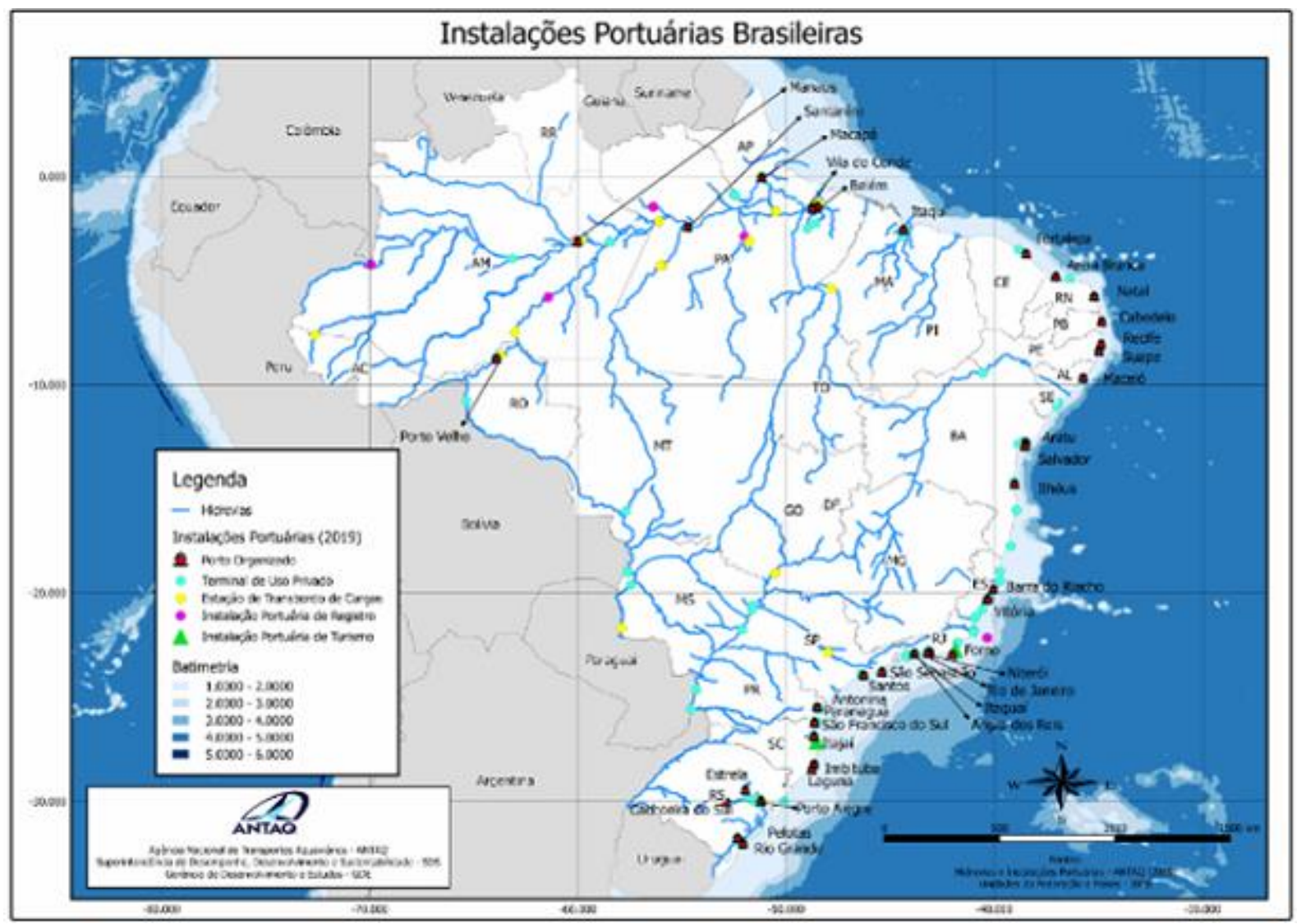

Fonte: ANTAQ (2019a). 
De acordo a ANTAQ (2019b), os portos públicos e os terminais privados brasileiros movimentaram, em 2018, 1,117 bilhão de toneladas, o que representa um crescimento de 2,7\% em relação ao ano de 2017 e de 33\% em relação ao ano de 2010. As mercadorias de maior movimentação no ano de 2018 foram: minério de ferro (407 milhões de toneladas), petróleo e derivados (203 milhões de toneladas) e contêineres (113 milhões de toneladas) e soja (102 milhões de toneladas).

Entre os portos públicos, destacaram-se, no ano de 2018, o Porto de Santos - SP, com 107,5 milhões de toneladas de cargas; o Porto de Itaguaí - RJ, com 56,6 milhões de toneladas; o Porto de Paranaguá - PR, com 48,5 milhões de toneladas; o Porto do Rio Grande - RS, com 27,2 milhões; e o Porto de Suape, com 23,4 milhões de toneladas. Em relação aos terminais privados, o Terminal de Ponta da Madeira (MA) liderou a movimentação de mercadorias, com 198,1 milhões de toneladas, seguido pelos portos de Tubarão (ES) (103,9 milhões de toneladas), Tebar (SP) (44,1 milhões de toneladas), Tebig (RJ) (42,9 milhões de toneladas) e Ilha Guaíba (RJ), com 41,2 milhões de toneladas (ANTAQ, 2019b). Verifica-se que o Terminal de Ponta da Madeira (MA), o Porto de Santos (SP) e o Porto de Tubarão (ES) lideraram o ranking da movimentação de cargas no ano de 2018. Juntos, esses portos movimentaram 409,5 milhões de toneladas, o que representa $36,7 \%$ da movimentação de mercadorias ocorrida no País (ANTAQ, 2019b).

Em relação ao número de portos e terminais, o estado do Espírito Santo é considerado o detentor do maior Complexo Portuário do Brasil (IDEIES, 2018). O início da atividade portuária no Estado se deu com o desenvolvimento da atividade cafeeira, por volta de 1870, com os embarques na parte sul da Ilha de Vitória, no atracadouro Cais do Imperador (IDEIES, 2018) e, atualmente, o Estado possui 2 Portos Organizados (Porto de Vitória e Barra do Riacho) e 11 Terminais de Uso Privado (TUP) distribuídos pelos $436 \mathrm{~km}$ de litoral (ANTAQ, 2019a). No Quadro 3, é apresentada a infraestrutura portuária atual do estado do Espírito Santo.

Quadro 3 - Infraestrutura portuária atual do estado do Espírito Santo

\begin{tabular}{|c|c|c|}
\hline CAIS & NOME & LOCALIZAÇÃO E CAMPO DE ATUAÇÃO \\
\hline 01 & $\begin{array}{l}\text { Terminal } \\
\text { Capixaba }\end{array}$ & $\begin{array}{l}\text { Barra Nova - São Mateus. Escoa o petróleo dos campos } \\
\text { terrestres do norte do Espírito Santo por navios }\end{array}$ \\
\hline
\end{tabular}




\begin{tabular}{|c|c|c|}
\hline & (Transpetro) & atracados em monoboia. \\
\hline 02 & Portocel & $\begin{array}{l}\text { Barra do Riacho - Aracruz. Especializado em celulose. } \\
\text { Opera também blocos de mármore e granito, além de } \\
\text { produtos siderúrgicos. }\end{array}$ \\
\hline 03 & $\begin{array}{l}\text { Terminal } \\
\text { Aquaviário Barra } \\
\text { do Riacho }\end{array}$ & $\begin{array}{l}\text { Barra do Riacho - Aracruz. Movimenta gás liquefeito } \\
\text { de petróleo (GLP) e gasolina natural (C5. }\end{array}$ \\
\hline 04 & $\begin{array}{l}\text { Complexo Portuário } \\
\text { de Tubarão }\end{array}$ & $\begin{array}{l}\text { Vitória, capital do Estado. Reúne cinco terminais: } \\
\text { Tubarão, Granéis Líquidos, Praia Mole, Produtos } \\
\text { Diversos e Produtos Siderúrgicos, a saber: }\end{array}$ \\
\hline 05 & $\begin{array}{l}\text { Terminal de } \\
\text { Tubarão }\end{array}$ & $\begin{array}{l}\text { Operado pela Vale. É o maior terminal de exportação } \\
\text { de pelotas e de minério de ferro do mundo. }\end{array}$ \\
\hline 06 & $\begin{array}{lr}\text { Terminal } & \text { de } \\
\text { Granéis } & \text { Líquidos } \\
\text { (TGL) } & \end{array}$ & $\begin{array}{l}\text { Especializado na movimentação de derivados do } \\
\text { petróleo. }\end{array}$ \\
\hline 07 & $\begin{array}{l}\text { Terminal de Praia } \\
\text { Mole }\end{array}$ & $\begin{array}{l}\text { Especializado em operações de descarga de navios com } \\
\text { carvão ( } 70 \% \text { do volume importado pelas siderúrgicas), } \\
\text { coque e antracito. }\end{array}$ \\
\hline 08 & $\begin{array}{lr}\text { Terminal } & \text { de } \\
\text { Produtos } & \text { Diversos } \\
\text { (TPD) } & \end{array}$ & $\begin{array}{l}\text { Sistema integrado de recepção, manuseio e } \\
\text { armazenagem de grãos (15\% das exportações do } \\
\text { Brasil) e fertilizantes ( } 8 \% \text { do volume importado). }\end{array}$ \\
\hline 09 & $\begin{array}{l}\text { Terminal de } \\
\text { Produtos } \\
\text { Siderúrgicos (TPS) }\end{array}$ & $\begin{array}{l}\text { Movimenta, além de produtos siderúrgicos, ferro gusa, } \\
\text { mármore/granito e veículos. Operado pelo consórcio } \\
\text { ArcelorMittal Tubarão, Usiminas e Gerdau Açominas. }\end{array}$ \\
\hline 10 & $\begin{array}{l}\text { Complexo do Porto } \\
\text { de Vitória }\end{array}$ & $\begin{array}{l}\text { Vitória, capital do Estado. Administrado pela } \\
\text { Companhia Docas do Espírito Santo (Codesa). } \\
\text { Movimenta carga geral por meio dos terminais Cais de } \\
\text { Vitória, Capuaba, Peiú, Atalaia, Flexibrás, TVV e } \\
\text { CPVV. }\end{array}$ \\
\hline 11 & $\begin{array}{l}\text { Terminal Vila Velha } \\
\text { (TVV) }\end{array}$ & $\begin{array}{l}\text { Vila Velha-ES. Especializado em contêineres operado } \\
\text { pela iniciativa privada (Log-In Internacional e } \\
\text { Logística). }\end{array}$ \\
\hline 12 & $\begin{array}{l}\text { Companhia } \\
\text { Portuária de Vila }\end{array}$ & $\begin{array}{l}\text { Vila Velha - ES. Atende às operações offshore de } \\
\text { exploração e produção de petróleo no Espírito Santo. }\end{array}$ \\
\hline
\end{tabular}




\begin{tabular}{|c|l|l|}
\hline 13 & $\begin{array}{l}\text { Velha - CPVV } \\
\text { Porto de Ubu } \\
\text { (Samarco) }\end{array}$ & $\begin{array}{l}\text { Anchieta - ES. Movimenta pelotas e de minério de } \\
\text { ferro, granéis sólidos e carga geral. Utilizado em } \\
\text { operações de supplyboats para indústria de petróleo e } \\
\text { outras. }\end{array}$ \\
\hline
\end{tabular}

Fonte: Governo ES (2019?), adaptado pelos autores.

Os portos capixabas movimentaram, em 2017, cerca de 148,3 milhões de toneladas, ranqueando o Estado com a quarta colocação em movimentação portuária no País, sendo superado apenas pelos estados do Maranhão, Rio de Janeiro e São Paulo (ANTAQ, 2019b). O porto mais diversificado é o Porto Organizado de Vitória, com 109 tipos de mercadorias diferentes; porém, a maior participação da movimentação portuária é representada pelo minério de ferro, carvão mineral, produtos siderúrgicos e celulose, exercida, principalmente, por navegação de longo curso (que ocorre entre portos de diferentes países) pelos Terminais de Uso Privado (IDEIES, 2018), o que está de acordo com Nota Técnica publicada pelo Instituto Jonas dos Santos Neves (IJSN, 2013). E, apesar da expressiva movimentação de cargas do sistema portuário capixaba, há novos os projetos de investimentos em portos no estado do Espírito Santo (Quadro 4), e, dentre eles, encontra-se o Porto Central.

Quadro 4 - Projetos de investimentos em Portos no estado do Espírito Santo

\begin{tabular}{|c|c|c|}
\hline CAIS & NOME & LOCALIZAÇÃO E CAMPO DE ATUAÇÃO \\
\hline 01 & Portocel (privado) & $\begin{array}{l}\text { Aracruz-ES. Especializado em celulose com projeto de } \\
\text { expansão para movimentação de carga geral. }\end{array}$ \\
\hline 02 & Imetame (privado) & $\begin{array}{l}\text { Aracruz-ES. Para apoio de atividades offshore com } \\
\text { possibilidade de diversificação de uso. }\end{array}$ \\
\hline 03 & $\begin{array}{l}\text { Itaoca } \\
\text { (privado) }\end{array}$ & $\begin{array}{l}\text { Itapemirim-ES. Para atender às demandas de serviços } \\
\text { logísticos offshore do mercado nacional de petróleo e } \\
\text { gás. }\end{array}$ \\
\hline 04 & $\begin{array}{l}\text { Porto } \\
\text { (privado) }\end{array}$ & $\begin{array}{l}\text { Presidente Kennedy-ES. Parceria entre a TPK } \\
\text { Logística e o Porto de Roterdã, maior porto marítimo } \\
\text { da Europa, o porto visa atender as demandas de } \\
\text { multicargas: contêiner, granel sólido (soja, minério, }\end{array}$ \\
\hline
\end{tabular}




\begin{tabular}{|c|c|c|}
\hline & & etc), granel líquido e apoio offshore. \\
\hline 05 & $\begin{array}{l}\text { Terminal Portuário } \\
\text { de Urussuquara - } \\
\text { Petrocity (privado) }\end{array}$ & $\begin{array}{l}\text { São Mateus-ES. Terminal de cargas gerais a ser } \\
\text { instalado com projeto de atender também às demandas } \\
\text { de serviços logísticos offshore do mercado nacional de } \\
\text { petróleo e gás. }\end{array}$ \\
\hline
\end{tabular}

Fonte: Governo ES (2019?), adaptado pelos autores.

A expectativa é que esses investimentos se concretizem e possam contribuir para a redução das tarifas portuárias e aprimorar a infraestrutura de acesso de novas mercadorias, possibilitando a chegada de navios maiores e rotas internacionais. Bem como, a implementação de portos pode trazer para a área consolidação de outras áreas do direito na região, como: o direito portuário, o direito aduaneiro, o direito marítimo, direito internacional, entre outros.

\section{LICENCIAMENTO DE PORTOS: COMPETÊNCIA, LICENÇAS E PROCEDIMENTOS}

A Constituição de 1988 expressa, no art. 23, inciso VI, que é competência da União, dos Estados, do Distrito Federal e do Município proteger o meio ambiente. O art. $7^{\circ}$, caput, XIV, b, da Lei Complementar n ${ }^{\circ}$ 140/2011 (BRASIL, 2011, on-line) expressa ser competência da União licenciar empreendimentos e atividades "localizados ou desenvolvidos no mar territorial, na plataforma continental ou na zona econômica exclusiva”. Destaca-se, porém, que apenas será de competência da União os portos organizados que movimentem carga em volume superior a 450.000 Twenty-foot Equivalent Units(TEU)/ano ou 15.000.000 t/ano, vide art. $3^{\circ}$ do Dec. 8.437/2015 (BRASIL, 2015, on-line).

O órgão competente da União para licenciar portos marítimos é o Instituto Brasileiro do Meio Ambiente e dos Recursos Naturais Renováveis (IBAMA), conforme citado no inciso I, $1^{\circ}$ do art. $4^{\circ}$ da Resolução CONAMA 237/97:

Art. $4^{\circ}$ - Compete ao Instituto Brasileiro do Meio Ambiente e dos Recursos Naturais Renováveis - IBAMA, órgão executor do SISNAMA, o licenciamento ambiental, a que se refere o artigo 10 da Lei ${ }^{\circ} 6.938$, de 31 de agosto de 1981, de empreendimentos e atividades com significativo impacto ambiental de âmbito nacional ou regional, a saber:

I - localizadas ou desenvolvidas conjuntamente no Brasil e em país limítrofe; no mar territorial; na plataforma continental; na zona econômica exclusiva; (...) (BRASIL, 1997, on-line). 
O IBAMA é uma autarquia federal ligada ao Ministério do Meio Ambiente que possui autonomia financeira e administrativa, que, como citado no inciso II do art. $2^{\circ}$ da Lei 7.735/89 (BRASIL, 1989), possui competência para:

Executar ações das políticas nacionais do meio ambiente, referentes às atribuições federais, relativas ao licenciamento ambiental, à autorização de uso dos recursos naturais e à fiscalização, monitoramento e controle ambiental, observadas as diretrizes emanadas do Ministério do Meio Ambiente (BRASIL, 1989, on-line).

A licença ambiental, de acordo com o inciso II, art. $1^{\circ}$ da Resolução 237/97 (CONAMA), é definida como:

\begin{abstract}
Ato administrativo pelo qual o órgão competente, estabelece condições, restrições e medidas de controle ambiental que deverão ser obedecidas pelo empreendedor, pessoa física ou jurídica, para localizar, instalar, ampliar e operar empreendimentos ou atividades utilizadoras dos recursos ambientais consideradas efetiva ou potencialmente poluidoras ou aquelas que, sob qualquer forma, possam causar degradação ambiental (BRASIL, 1997, online).
\end{abstract}

Ressalta-se que a licença ambiental é a outorga concedida pelo Poder Público a quem pretende exercer uma atividade potencialmente nociva ao meio ambiente. Assim, todo aquele que pretender construir, instalar, ampliar e colocar em funcionamento estabelecimentos e atividades utilizadoras de recursos ambientais, considerados efetiva ou potencialmente poluidores, deverá requerer, perante o órgão público competente, a licença ambiental (SIRVINSKAS, 2018).

Durante o processo de licenciamento ambiental, o Poder Público poderá expedir três tipos de licenças, conforme estabelece o art. $8^{\circ}$ da Resolução n. 237/97 do CONAMA, a saber: Licença Prévia, Licença de Instalação e a Licença de Operação. A Licença Prévia é concedida na fase inicial, na qual há o planejamento do empreendimento ou da atividade, nessa licença, é aprovada a localização e a concepção deste, além disso, tal licença atesta a viabilidade ambiental e estabelece requisitos a serem cumpridos nas próximas fases do processo de licenciamento. A Licença de Instalação autoriza a instalação do empreendimento de acordo com as especificações constantes nos planos, programas e projetos aprovados, incluindo as medidas de controle ambiental e demais condicionantes, da qual constituem motivo determinante. $\mathrm{E}$ a Licença de Operação autoriza a operação ou empreendimento, após a verificação do 
efetivo cumprimento do que consta das licenças anteriores, com as medidas de controle ambiental e condicionantes determinadas para a operação (TRENNEPOHL, 2018).

Cabe asseverar que a emissão de uma das licenças não garante a emissão da próxima licença. Nesse sentido, Trennepohl (2018, p. 97-98) conclui que: “O pedido de licenciamento apresentado num órgão ambiental não significa, obrigatoriamente, que este o conduzirá até o final. Nem emissão de uma das licenças torna o emitente prevento para a concessão das demais".

É importante salientar que, dentro desses prazos, há diversas atividades que o empreendedor deve cumprir para que consiga tais licenças, devendo este arcar integralmente com todas as demandas exigidas no processo licenciatório, inclusive ao se tratar dos custos do órgão licenciador, conforme expresso no Manual de Licenciamento Ambiental de Portos da Agencia Nacional de Transportes Aquaviários (ANTAQ, 2012?).

O art. 10 da Resolução CONAMA n. 237/1997 informa que o procedimento licitatório deverá obedecer algumas etapas, colocadas por Édis Milaré (MILARÉ, 2018, on-line) como oito fases que o empreendedor precisa seguir. Em um primeiro momento, o órgão licenciador, que, neste caso é o IBAMA, deverá, com a participação do empreendedor, definir quais são os "documentos, projetos e estudos ambientais necessários ao início do processo de licenciamento".

Nessa primeira fase, as atividades que possuem alto grau de degradação dependerão do Estudo Prévio de Impacto Ambiental (EIA) e do Relatório de Impacto ao Meio Ambiente (RIMA), como é o caso dos portos, conforme expressa o art. $2^{\circ}$, inciso III da Resolução CONAMA 001/1986 (MILARÉ, 2018). A utilização desses instrumentos técnicos é um exemplo prático da incorporação do princípio da prevenção no licenciamento ambiental de portos, que busca, por meio de medidas acautelatórias, evitar a ocorrência de danos ao meio ambiente antes que o empreendimento e atividades potencialmente poluidoras possam ser implementadas.

O Manual de Licenciamento Ambiental de Portos da ANTAQ define EIA como um "conjunto de atividades técnicas e científicas destinadas a identificar previamente a magnitude e valorar os impactos de um projeto e suas alternativas, realizado e apresentado em forma de relatório" (ANTAQ, 2012, on-line). O EIA deve estar de acordo com o Termo de Referência, que, de acordo com o art. $2^{\circ}, \mathrm{X}$, da Portaria 
Interministerial 60/2015, é um "documento elaborado pelo IBAMA que estabelece o conteúdo necessário dos estudos a serem apresentados em processo de licenciamento ambiental” (BRASIL, 2015, on-line). A ANTAQ, ainda, expressa que o RIMA é o documento que apresenta as conclusões do EIA, devendo este estar em uma linguagem clara para que as comunidades afetadas pelo empreendimento possam compreender.

Vale destacar que, em estudos de impactos ambientais de portos, uma das peculiaridades, que difere dos demais tipos de licenciamento ambiental, é a descrição do fundo do mar e da costa marítima, o que é feito por meio da oceanografia. A oceanografia engloba tanto a formação geológica da área analisada, a formação química e a poluição marítima, quanto a composição biológica, a biota e ecologia dos oceanos (PORTAL EDUCAÇÃO, 2019?).

O requerimento da licença é feito na segunda fase e deverá ser publicamente anunciado, além disso, é fundamental que, entre os documentos apresentados para requerer a licença, esteja a certidão da Prefeitura Municipal que conterá uma declaração se o tipo e o local do empreendimento estão de acordo com a lei que versa sobre o uso e ocupação do solo. Em seguida, na terceira fase, o órgão licenciador realiza a análise dos documentos, projetos e dos estudos ambientais apresentados e, caso seja necessário, ele realizará vistorias técnicas (MILARÉ, 2018).

$\mathrm{Na}$ quarta fase, o órgão licenciador aceita a documentação que foi apresentada ou, em caso contrário, devolve e solicita esclarecimentos e complementação das informações que forem omissas entre os documentos. O empreendedor é comunicado para prestar esclarecimentos e complementações uma única vez através de notificação e, de acordo com o art. 15, caput da Resolução CONAMA no 237/1997, deverá atender à solicitação em um prazo máximo de 4 (quatro) meses, contados do recebimento da notificação. O parágrafo único do corrente artigo dispõe que "o prazo estipulado no caput poderá ser prorrogado, desde que justificado e com a concordância do empreendedor e do órgão ambiental competente" (MILARÉ, 2018, p.1035).

$\mathrm{Na}$ quinta fase, ocorre a audiência pública ou sua dispensa. A audiência pública é o instrumento que permite à população, que será afetada, a participação na tomada de decisões e compreensão dos impactos ambientais e do benefício que o empreendimento trará para a comunidade. Na sexta fase, em busca de compreender melhor as questões relevantes sobre o a viabilidade ambiental do empreendimento, pode ocorrer a 
solicitação de esclarecimentos e complementações decorrentes da audiência pública, podendo, inclusive, designar nova audiência pública, conforme o art. $23, \S 1^{\circ}$, da IN IBAMA 184/2008, alterada pela IN 14/2011 (IBAMA, 1990) e reportada por Milaré (2018).

Na sétima fase, há a emissão de parecer técnico conclusivo, bem como a emissão de parecer jurídico. Por fim, o deferimento ou indeferimento do pedido de licença ocorre na oitava fase que deverá ser público e seu desdobramento se dá em três etapas: Licença Prévia, Licença de Instalação e Licença de Operação.

Entre as licenças, é importante frisar que, para a concessão Licença de Instalação, alguns dos documentos técnicos necessários são: Projeto Básico Ambiental (PBA), Plano de Compensação Ambiental (PCA) e quando impender, Inventário Florestal para que seja emitida autorização de supressão vegetal e o Plano de Recuperação de Área Degradada (PRAD) (MILARÉ, 2018). Além disso, iniciadas a implantação e a operação do empreendimento, o art. 19, $\S 3^{\circ}$ do Decreto 99.274/1990 (BRASIL, 1990, on-line), expõe que, antes da expedição das licenças, os Órgãos Setoriais do IBAMA deverão realizar a comunicação deste fato às entidades que financiam o empreendimento.

Uma das particularidades no processo de licenciamento ambiental de portos é o parecer expedido pela Marinha do Brasil, por meio da Diretoria de Portos e Costas/Capitania dos Portos. De acordo com a ANTAQ (2019), o empreendedor deverá apresentar à Capitania dos Portos, Delegacia ou Agência da área de jurisdição, um requerimento solicitando um Parecer no que concerne ao ordenamento do espaço aquaviário e à segurança da navegação. Somente após o Parecer favorável da Marinha é que o empreendedor poderá iniciar o Processo de Licenciamento Ambiental junto ao Órgão Ambiental competente. Ressalta-se ainda que, após a obtenção do Licenciamento Ambiental de Instalação e das demais autorizações legais de outros órgãos públicos, o empreendedor deverá comunicar formalmente à Marinha a data de início das obras e seu término previsto. As informações e a documentação que devem constar desse requerimento são estabelecidas pelas "NORMAS DA AUTORIDADE MARÍTIMA No 11", conhecidas como "NORMAM 11" (ANTAQ, 2019). Nota-se, assim, a relação do direito ambiental com o direito marítimo.

\section{O LICENCIAMENTO AMBIENTAL DO PORTO CENTRAL DO MUNICÍPIO}




\section{DE PRESIDENTE KENNEDY}

No licenciamento ambiental do Porto Central, no município de Presidente Kennedy, o processo encontra-se, atualmente, com a etapa de licença de instalação concedida, sendo possível o acompanhamento do processo pelo site do IBAMA, sob o n 02001.006386/2011-40. No Quadro 5, é apresentado um extrato do processo de licenciamento ambiental do Porto Central, contemplando todos os documentos do processo e suas respectivas datas.

Verifica-se que o processo de licenciamento ambiental do Porto Central foi iniciado no dia 29/08/2011 e que, até o presente momento (25 de julho de 2019), o último ato praticado foi no dia 01/03/2018. Dentro deste interstício, tiveram a concessão de duas importantes licenças ambientais: a licença prévia e a licença de instalação.

Como é notório, para a concessão de licença prévia, é imprescindível o cumprimento de uma série de documentos técnicos, entre as quais se destacam o EIA e o RIMA (BRASIL, 1981), ambos realizados e apresentados para a sociedade através de Audiência Pública no dia 07/11/2013, conforme verificado no Quadro 5, números 11, 12 e 14, respectivamente. Para a realização desses documentos, é imperioso a observação dos critérios básicos e das diretrizes gerais para aplicação da Avaliação de Impacto Ambiental (BRASIL, 1986), na qual cada estudo dependerá da especificidade do empreendimento.

Para o que o EIA/RIMA fosse aprovado, fez-se necessário o cumprimento das exigências expressas no Termo de Referência para a elaboração do EIA e do RIMA, descrito no $\mathrm{n}^{\mathrm{o}} 7$ do Quadro 5. É possível verificar, através dos Pareceres Técnicos de $\mathrm{n}^{\circ}$ 11 e 12, que houve a necessidade de 2 (dois) checklists do EIA, haja vista que o IBAMA concluiu que, no primeiro checklist, não foram apresentados todos os requisitos exigidos no Termo de Referência, requerendo, portanto, as modificações desses itens ou a justificativa de não apresentá-los, e ou as adequações necessárias para a apresentação de uma nova versão do EIA, o que foi realizado no documento de $\mathrm{n}^{\mathrm{o}} 12$ (PAR. 004861/2013 e 007757/2013).

$\mathrm{Na}$ audiência pública, instrumento democrático do processo de licenciamento ambiental (BRASIL, 1987; BRASIL, 1988), foi apresentado o projeto do Porto Central e o RIMA em linguagem simplificada para a comunidade convocada, visando dirimir dúvidas sobre os impactos negativos e positivos do projeto e promover a participação e 
o envolvimento popular como fonte essencial na defesa do meio ambiente. De acordo com o site do Porto Central, o evento contou "com a presença de cerca de 500 pessoas do município Presidente Kennedy e cidades vizinhas, tais como: Marataízes e São Francisco de Itabapoana- RJ" (PORTO CENTRAL, 2013, on-line), e foi apresentado por uma equipe multidisciplinar.

QUADRO 5 - Extrato do processo de licenciamento ambiental do Porto Central.

\begin{tabular}{|c|c|c|}
\hline $\mathbf{N}^{\mathbf{0}}$ & ASSUNTO & DATA \\
\hline 1 & $\begin{array}{l}\text { Orientações para o estabelecimento do Programa de Educação } \\
\text { Ambiental no âmbito do licenciamento ambiental. }\end{array}$ & $29 / 08 / 2011$ \\
\hline 2 & Parecer Técnico 686/2016-20 Nota Técnica n 39/11 & $29 / 08 / 2011$ \\
\hline 3 & Parecer Técnico 686/2016-20 Nota Técnica n 42/11 & $02 / 09 / 2011$ \\
\hline 4 & Relatório de Vistoria TPK/Ferrous & $02 / 01 / 2012$ \\
\hline 5 & $\begin{array}{l}\text { Orientações para elaboração de Programa de Comunicação Social } \\
\text { (PCS) executado no âmbito do licenciamento ambiental. }\end{array}$ & $29 / 02 / 2012$ \\
\hline 6 & $\begin{array}{l}\text { Minuta de Termo de Referência - Procedimentos para Solicitação } \\
\text { de Autorização de Coleta, Captura e Transporte de Material } \\
\text { Biológico }\end{array}$ & $01 / 03 / 2012$ \\
\hline 7 & Minuta do Termo de Referência para elaboração do EIA/RIMA & $07 / 03 / 2012$ \\
\hline 8 & $\begin{array}{l}\text { Análise de Solicitação de Autorização de Captura, Coleta e } \\
\text { Transporte de Material Biológico (Abio) }\end{array}$ & $18 / 09 / 2012$ \\
\hline 9 & Abio 153/2012 & $20 / 09 / 2012$ \\
\hline 10 & Abio 154/2012 & $20 / 09 / 2012$ \\
\hline 11 & Avaliação preliminar (checklist) do EIA/RIMA & $27 / 05 / 2013$ \\
\hline 12 & Procedimento de verificação preliminar (checklist) do EIA/RIMA & $30 / 07 / 2013$ \\
\hline 13 & Solicitação da Licença Prévia - LP & $14 / 08 / 2013$ \\
\hline 14 & $\begin{array}{l}\text { Ata de Audiência Pública referente ao empreendimento Porto } \\
\text { Central }\end{array}$ & $07 / 11 / 2013$ \\
\hline 15 & Histórico processo Porto Central & $19 / 05 / 2014$ \\
\hline
\end{tabular}




\begin{tabular}{|c|c|c|}
\hline 16 & $\begin{array}{l}\text { Análise da viabilidade ambiental do empreendimento Porto Central, } \\
\text { pretendido para ser implantado no Município de Presidente } \\
\text { Kennedy, Estado do Espírito Santo }\end{array}$ & $22 / 07 / 2014$ \\
\hline 17 & Análise da viabilidade ambiental do empreendimento & $22 / 07 / 2014$ \\
\hline 18 & Análise de informações e estudos complementares ao EIA & $17 / 11 / 2014$ \\
\hline 19 & Parecer Técnico 0048662014 COPAH/IBAMA & $04 / 12 / 2014$ \\
\hline 20 & Licença Prévia - LP 498/2014 & $05 / 12 / 2014$ \\
\hline 21 & Análise do Plano Amostral do Pacote Sedimentar a ser dragado & $12 / 05 / 2015$ \\
\hline 22 & Solicitação de Licença de Instalação - LI & $03 / 08 / 2015$ \\
\hline 23 & Parecer Técnico 686/2016-20 Parecer Técnico 3697/15-81 & $16 / 09 / 2015$ \\
\hline 24 & $\begin{array}{l}\text { Análise da solicitação de Licença de Instalação do empreendimento } \\
\text { Porto Central }\end{array}$ & $02 / 03 / 2016$ \\
\hline 25 & Parecer Técnico 686/2016-20 Layout do empreendimento & $02 / 03 / 2016$ \\
\hline 26 & $\begin{array}{l}\text { Questionamentos a respeito do Parecer } n^{\circ} \text { 686/2016-20, de } \\
02 / 03 / 2016\end{array}$ & $20 / 04 / 2016$ \\
\hline 27 & Questionamentos a respeito do Parecer $\mathrm{n}^{\circ}$ 686/2016-20 & $28 / 04 / 2016$ \\
\hline 28 & Anexo Parecer 3871/2016-76 & $04 / 07 / 2016$ \\
\hline 29 & Anexo Parecer 3871/2016-76 & $10 / 10 / 2016$ \\
\hline 30 & Anexo Parecer 3871/2016-76 & $14 / 10 / 2016$ \\
\hline 31 & $\begin{array}{l}\text { Análise do PBA e do atendimento às condicionantes da LP } \\
498 / 2014\end{array}$ & $14 / 10 / 2016$ \\
\hline 32 & Anexo Parecer 3871/2016-76 & $14 / 10 / 2016$ \\
\hline 33 & Anexo Parecer 3871/2016-76 & $14 / 10 / 2016$ \\
\hline 34 & Abio 865/2017 & $18 / 10 / 2017$ \\
\hline 35 & Abio 875/2017 & $10 / 11 / 2017$ \\
\hline 36 & Licença de Instalação - LI 1203/2018 & $01 / 03 / 2018$ \\
\hline 37 & Parecer Técnico 686/2016-20 Despacho 31669 & $08 / 01 / 2015$ \\
\hline
\end{tabular}




\section{$38 \quad$ Parecer 3871/2016-76}

Fonte: IBAMA (2019), adaptado pelos autores

A licença prévia, solicitada em 14/08/2013 e concedida em 05/12/2015, com prazo de validade de 4 (quatro) anos, possibilitou a complementação de estudos e análise referentes ao EIA e a elaboração do RIMA, o que está de acordo com a determinação de praxe do IBAMA. Ressalta-se que, neste período, foram também realizadas, entre outros, a execução do Programa de Compensação de Atividade Pesqueira (PCAP), juntamente com as comunidades pesqueiras da região, priorizando projetos que apresentam benefícios coletivos para a cada comunidade envolvida.

Outra ação realizada neste período foi o ajuste do local de descarte marinho, fundamentado por pesquisas em 5 (cinco) áreas marinhas que objetivaram selecionar uma área viável e sustentável para o descarte marinho de material dragado, de modo a minimizar os impactos negativos aos meios físicos e bióticos, e garantir uma distância segura da costa e menor interferência com a área de pesca da região (PORTO CENTRAL, 2018). Os resultados dessas pesquisas consubstanciaram os termos do PCAP de cada comunidade. Devido a isso, no dia 25/01/2018, ocorreu, em Presidente Kennedy, uma reunião pública, coordenada por representantes do IBAMA, com o intuito de esclarecer a alteração da área de descarte marinha, evidenciando, assim, maior segurança jurídica ao processo de licenciamento ambiental do porto (PORTO CENTRAL, 2018).

Vale ressaltar que a Praia das Neves e a Praia de Marobá são as únicas praias do município de Presidente Kennedy. Das duas praias, a que apresenta maior número de habitantes é Marobá, estimada em 520 pessoas (PMK, 2019). Nela, existe uma associação de pescadores, a Associação de Pescadores de Marobá, formada por cerca de 60 pescadores que sobrevivem da pesca da peroá, curvina, arraia, lagosta, cação, pargo, baiacu, pescadinha (PROMAR, 2005). Essa característica socioeconômica e cultural da região, como ressalta Meira (2017), deveria ser melhor investigada para a instalação do Porto Central. Salienta-se ainda que a Praia das Neves abriga um importante centro histórico, o Santuário de Nossa Senhora das Neves, cujo tombamento foi aprovado pelo Conselho Estadual de Cultura como Patrimônio Histórico e Artístico Estadual por meio 
da Resolução n 2/2009 (ESPÍRITO SANTO, 2009, on-line). A igreja foi construída pelos padres jesuítas no século XVII com ajuda dos escravos e índios catequizados. Um marco do nascimento da cidade.

A licença de instalação, solicitada em 03/08/2015, foi concedida no dia 02/03/2018, ou seja, entre a licença prévia e a licença mencionada teve um intervalo de tempo de aproximadamente 3 (três) anos e 4 (quatro) meses, o que está de acordo com o prazo de validade estipulado pelo IBAMA para licença prévia. Para a licença de instalação, o IBAMA concedeu ao Porto Central um período de 6 (seis) anos para que o empreendimento realize a instalação do porto e cumpra com as medidas de controle ambiental e condicionantes, como é, entre outros, o caso do Programa de Recuperação da Área Degradada (PRAD), ainda não realizado (LI 1203/2018).

Com a concessão da licença de instalação, o Porto Central será responsável pela construção portuária básica, como: um canal de acesso de 25 metros de profundidade, quebra-mar, cais, vias de acessos internos, utilidades (PORTO CENTRAL, 2018). Além disso, fará parte do Porto Central uma área de 2.000 hectares para que indústrias ou empresas possam construir e operar os seus próprios terminais, o que já está acontecendo.

Ao realizar uma visita de campo na área de estudo, no dia 13 de julho de 2019, foi possível constatar que, no entorno da área do Porto Central, já existem algumas placas de sinalização de empresas que buscam abrir filiais na localidade através de outros processos de licenciamento, como é o caso da empresa Ferrous Resources do Brasil S.A, que atua na área na pesquisa, prospecção, exploração, beneficiamento e comercialização de minério de ferro (FERROUS, 2019) e da empresa Nova K Logística Ltda, especializada na coordenação e desenvolvimento de projetos logísticos para este fim (NOVAK, 2019) (Ilustração 5). 
ILUSTRAÇÃO 5 - Placas de sinalização presentes na área de influência de algumas empresas potenciais que atuarão do Porto Central, Presidente Kennedy- ES: A.

Ferrous e B. Nova K
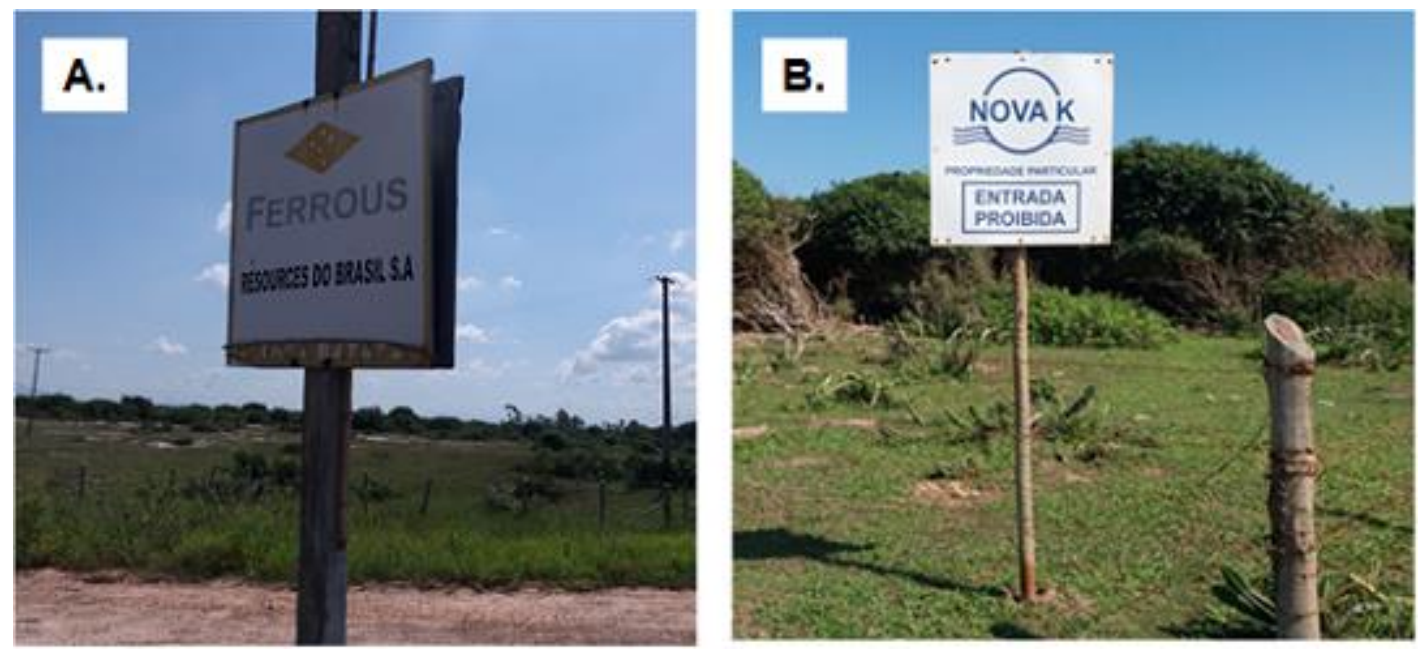

Fonte: Ferrari (2019).

Como abordado acima, o Porto Central já obteve a licença prévia e a licença de instalação. Sendo assim, para a conclusão do processo de licenciamento ambiental, o empreendimento necessita concluir a licença de instalação dentro do seu prazo de validade de 6 (seis) anos, ou seja, em 2024, mediante a concessão da licença de operação. Considerando que o prazo de validade da licença de operação é de, no mínimo 4 (quatro) anos e no máximo 10 (dez), estima-se que o fim do processo de licenciamento ambiental do Porto Central acontecerá em 2034.

\section{CONSIDERAÇÕES FINAIS}

Constatou-se que o licenciamento ambiental de portos é um procedimento administrativo necessário para viabilizar tais empreendimentos ou construções devido a sua potencialidade poluidora e de degradação ambiental. O procedimento licenciatório compreende três licenças ambientais: licença prévia, licença de instalação e licença de operação.

Verificou-se que o Porto Central é um projeto privado, cuja localização fica próxima à fronteira do estado do Espírito Santo com o Rio de Janeiro, caracterizado como uma Joint Venture, composta pelo Porto de Roterdã e pela TPK Logística S.A., e como cluster, no modelo de condomínio portuário. Percebeu-se ainda que a escolha do município de Presidente Kennedy como sede para o Porto Central se deve, entre outros, 
a área plana, de baixa densidade populacional e pela proximidade com vias importantes como a BR 101, sendo estes aspectos positivos.

Durante o processo de licenciamento, especialmente no EIA/RIMA, foi realizado o Programa de Compensação de Atividade Pesqueira, juntamente com as comunidades pesqueiras da região, bem como o ajuste do local de descarte marinho para menor interferência com a área de pesca. Entre as externalidades negativas potenciais, citam-se o descarte marinho de material dragado, a supressão da restinga na área de construção do empreendimento e os impactos socioeconômicos e culturais nas comunidades pesqueiras e no Santuário de Nossa Senhora das Neves, na área de influência do Porto.

Ressalta-se que, em todas as fases do licenciamento, é necessário o monitoramento dos impactos negativos, a fim de minimizar os danos provocados ao meio ambiente, aliando desenvolvimento econômico e preservação ambiental.

Constatou-se que o licenciamento ambiental do Porto Central de Presidente Kennedy (ES) foi iniciado em 2011 e ainda está em andamento, sob a competência do IBAMA. Até a presente data, foram concedidas a este empreendimento duas licenças ambientais: a licença prévia e a licença de instalação. Em 2018, o IBAMA concedeu a licença de instalação com o prazo de validade de 6 (seis) anos e que se o Porto Central cumprir com os procedimentos necessários, poderá obter a licença de operação em 2024.

\section{REFERÊNCIAS}

AGÊNCIA NACIONAL DE TRANSPORTES AQUAVIÁRIOS (ANTAQ). Informações Geográficas: Elementos dos Transportes Aquaviários. 2019a. Disponível em: <http://portal.antaq.gov.br/index.php/informacoes-geograficas/>. Acesso em: 27 mar. 2019.

. ANTAQ divulga os números da movimentação portuária de 2018. 2019b. Disponível em: <http://portal.antaq.gov.br/index.php/2019/02/12/antaq-divulga-osnumeros-da-movimentacao-portuaria-de-2018/> . Acesso em: 24 mar. 2019.

Manual de Licenciamento Ambiental de Portos. 2012? Disponível em: $<$ http://web.antaq.gov.br/portalv3/pdf/MeioAmbiente/manual_de_licenciamento_ambie ntal_nos_portos_(2).pdf >. Acesso em: 21 Mar. 2019.

BARROS, C. F. S. Procedimento para classificação de portos organizados brasileiros. 2013. 126f. Dissertação de Mestrado - Universidade de Brasília. Faculdade 
de Tecnologia Departamento de Engenharia Civil e Ambiental. Área: Transportes. Brasília, 2013. Disponível em: <https://repositorio.unb.br/bitstream/10482/13881/1/2013_CristianeFerreiraSilvaBarros. pdf>. Acesso em: 21 mai.2019.

BRASIL. Constituição (1988). Constituição da República Federativa do Brasil. Brasília, DF: Senado Federal: Centro Gráfico, 1988, 292 p.

Lei Federal No 6.938, de 31/08/1981. Política Nacional do Meio Ambiente PNMA. 1981. Lex: Coletânea de Legislação e Jurisprudência. Disponível em: <http://www.planalto.gov.br/ccivil_03/Leis/L6938.htm>. Acesso em: 26 mar. 2019.

Decreto $\mathrm{N}^{\circ}$ 99.274, 6 de junho de 1990. Dispõem, respectivamente sobre a criação de Estações Ecológicas e Áreas de Proteção Ambiental e sobre a Política Nacional do Meio Ambiente, e dá outras providências. Lex: Coletânea de Legislação e Jurisprudência.

Disponível em:<http://www.planalto.gov.br/ccivil_03/decreto/Antigos/D99274.htm> Acesso em: 18 abr. 2019.

Lei $N^{o} 7.735$, de 22 de Fevereiro de 1989. Dispõe sobre a extinção de órgão e de entidade autárquica, cria o Instituto Brasileiro do Meio Ambiente e dos Recursos Naturais Renováveis e dá outras providências. Lex: Coletânea de Legislação e Jurisprudência. Disponível em: <http://www.planalto.gov.br/ccivil_03/LEIS/L7735.htm>. Acesso em: 29 jun. 2020.

Lei $N^{\circ}$ 8.630, de 25 de Fevereiro de 1993. Lei de Modernização dos Portos. Brasília: Presidência da República. Lex: Coletânea de Legislação e Jurisprudência. Disponível em: <https://www2.camara.leg.br/legin/fed/lei/1993/lei-8630-25-fevereiro1993-363250-norma-pl.html >. Acesso em: 23 mar. 2020.

Lei 12.651, de 25 de Maio de 2012. Código Florestal Brasileiro. Brasília: Presidência da República. Lex: Coletânea de Legislação e Jurisprudência. Disponível em: <http://www.planalto.gov.br/ccivil_03/_ato2011-2014/2012/lei/112651.htm>. Acesso em: 18 abr. 2019.

Portaria Interministerial, de 24 de Março de 2015. Dispõe procedimentos administrativos que disciplinam a atuação dos órgãos e entidades da administração pública federal em processos de licenciamento ambiental de competência do Instituto Brasileiro do Meio Ambiente e dos Recursos Naturais Renováveis-IBAMA. Lex: Coletânea de Legislação e $<$ http://portal.iphan.gov.br/uploads/legislacao/Portaria_Interministerial_60_de_24_de_ marco_de_2015.pdf Portaria Interministerial 60/2015>. Acesso em: 30 mar. 2019.

Portaria Interministerial $\mathrm{n}^{\mathrm{o}}$ 425/2011, de 26 de Outubro de 2011. Institui o Programa Federal de Apoio à Regularização e Gestão Ambiental Portuária - PRGAP de portos e terminais portuários marítimos. Lex: Coletânea de Legislação e Jurisprudência. Disponível

em: 
<http://www.suape.pe.gov.br/images/publicacoes/Portaria/Portaria_Interministerial_M MA.SEP.PR_no_425.2011.pdf >. Acesso em: 28 mar. 2019.

. Lei 12.815, de 5 de Junho de 2013. Lei de Modernização dos Portos. Brasília: Presidência da República. Lex: Coletânea de Legislação e Jurisprudência. Disponível em: <http://www.planalto.gov.br/ccivil_03/_Ato2011-2014/2013/Lei/L12815.htm>. Acesso em: 23 mar. 2019.

Decreto 8.437, de 22 de abril de 2015. Regulamenta o disposto no art. $7^{\circ}$, caput, inciso XIV, alínea " $h$ ", e parágrafo único, da Lei Complementar $n{ }^{\circ} 140$, de 8 de dezembro de 2011, para estabelecer as tipologias de empreendimentos e atividades cujo licenciamento ambiental será de competência da União. Lex: Coletânea de Legislação e Jurisprudência. Disponível em: <http://www.planalto.gov.br/ccivil_03/_Ato20152018/2015/Decreto/D8437.htm>. Acesso em: 30 jun. 2020.

Resolução CONAMA No 237, de 19/12/1997. Dispõe sobre a revisão e complementação dos procedimentos e critérios utilizados para o licenciamento ambiental. Lex: Coletânea de Legislação e Jurisprudência. Disponível em: <http://www2.mma.gov.br/port/conama/legiabre.cfm?codlegi=237>. Acesso em: 26 mar. 2019.

Resolução CONAMA No 001, de 23 de janeiro de 1986. Dispõe sobre os critérios básicos e as diretrizes gerais para uso e implementação da Avaliação de Impacto Ambiental como um dos instrumentos da Política Nacional do Meio Ambiente. Lex: Coletânea de Legislação e Jurisprudência. Disponível em:< https://www.ibama.gov.br/sophia/cnia/legislacao/MMA/RE0001-230186.PDF>. Acesso em: 20 jul. 2019.

Resolução CONAMA No 009, de 3 de dezembro de 1987. Dispõe sobre a realização de Audiências Públicas no processo de licenciamento ambiental. Lex: Coletânea de Legislação e Jurisprudência. Disponível em:< http://www2.mma.gov.br/port/conama/legiabre.cfm?codlegi=60>. Acesso em: $20 \mathrm{jul}$. 2019.

ESPÍRITO SANTO (ESTADO). SECRETARIA DE ESTADO DA CULTURA. CONSELHO ESTADUAL DE CUTURA. Arquitetura. Secretaria de Estado da Cultura. Conselho Estadual de Cultura. Vitória: SECULT, 2009. 560 p.

\section{FERRARI, S. L. Licenciamento ambiental do Porto Central de Presidente}

Kennedy - um estudo de caso. 2019. 48 f. TCC (Graduação em Direito) - Faculdade de Direito de Cachoeiro de Itapemirim (FDCI), Cachoeiro de Itapemirim, 2019.

FERROUS. Quem somos. Disponível em: <https://www.ferrous.com.br/>. Acesso em: 25 jul. 2019.

GALVÃO, C. B.; ROBLES, L. T.; GUERISE, L. The Brazilian seaport system: A post1990 institucional and economic review. Research in Transportation Business \& Management, v. 8, p. 17-29, 2013. 
GIL, A. C. Como elaborar projetos de pesquisa. São Paulo: Atlas, 2010. 184 p.

GOVERNO ES. Portos. 2019?. Disponível em: < https://www.es.gov.br/portos-2>. Acesso em: 23 mar. 2019.

INSTITUTO BRASILEIRO DO MEIO AMBIENTE E DOS RECURSOS NATURAIS RENOVÁVEIS (IBAMA). Instruções normativas, 2008. Disponível em: <http://www.icmbio.gov.br/cepsul/images/stories/legislacao/Instrucao_normativa/2008/ in_ibama_184_2008_licenciamentoambientalfederal_revg_in_65_2005_altrd_in_ibama _14_2011.pdf>. Acesso em: 17 abr. 2019.

INSTITUTO BRASILEIRO DE GEOGRAFIA E ESTATISTICA (IBGE). Cidades e Estados. 2019?. Disponível em: <https://www.ibge.gov.br/cidades-e-estados.html>. Acesso em: 18 abr. 2019.

INSTITUTO DE DESENVOLVIMENTO EDUCACIONAL E INDUSTRIAL DO ESPÍRITO SANTO (IDEIES). A atividade portuária no Espírito Santo: Estrutura e potencialidades. Fato Econômico Capixaba, v. 2, n. 10, p. 1-4, 2018.

\section{INSTITUTO JONAS DOS SANTOS NEVES (IJSN). NT 39 - Desempenho no Setor

Portuário do Espírito Santo. 2013. Disponível em:
<http://www.ijsn.es.gov.br/artigos/3794-nt-39-desempenho-no-setor-portuario-doespirito-anto?highlight=WyJudCIsMzksIm50IDM5Il0=>. Acesso em: 31 mar. 2019.

ES em Mapas: Presidente Kennedy. 2019?. Disponível em: <http://www.ijsn.es.gov.br/mapas/>. Acesso em: 37 abr. 2019b.

LAM, J. S. L., ZHANG, W. Analysis on development interplay between port and maritime cluster. In: Anais...INTERNATIONAL WORKSHOP ON PORT ECONOMICS, 1, 2011, Singapore. Disponível em: <https://www.fas.nus.edu.sg/ecs/events/pe2011/Lam.pdf>. Acesso em: 31 mar. 2019.

MEIRA, A. C. H. “O!! Você vai construir por cima de mim!!": Desenvolvimento, conflito ambiental e disputas por justiça no litoral Sul do Espírito Santo, Brasil. 2017. 196 f. Tese (Doutorado). Universidade Federal do Rio Grande do Sul. Programa de Pósgraduação em Desenvolvimento Rural, Porto Alegre, RS, 2017.

MILARÉ, É. Direito do Ambiente. 11 ed. rev. atual. e ampl. São Paulo: Thomson Reuters Brasil, 2018.

NOVA K LOGISTÍCA LTDA. Organização logística do transporte de carga. Disponível em: < https://www.consultasocio.com/q/sa/fabricio-cardoso-freitas>. Acesso em: 25 jul. 2019.

PORTAL EDUCAÇÃO. Oceanografia. 2019?. Disponível em: < https://www.portaleducacao.com.br/conteudo/artigos/biologia/oceanografia/8890>. Acesso em: 23 jul. 2019. 
PORTO CENTRAL. O projeto do Porto Central. Disponível em: < http://www.portocentral.com.br/pb/o-projeto/\#secao-layout>. Acesso em: 7 abr. 2019.

Audiência Pública. 2013. Disponível em:

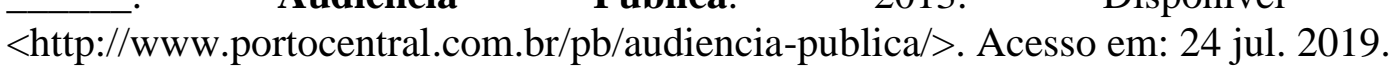

PORTOFROTTERDAM. Highlightsofthe 2017 Annual Report. Disponível em: < https://www.portofrotterdam.com/en/port-authority/about-the-port-

authority/finance/annual-reports>. Acesso em: 14 abr. 2019.

PREFEITURA MUNICIPAL DE PRESIDENTE KENNEDY (PMPK). Planejamento Estratégico de Presidente Kennedy 2018-2035. Futura, 2018. 102p.

PROGRAMA DAS NAÇÕES UNIDAS PARA O DESENVOLVIMENTO (PNUD). O que é desenvolvimento humano? 2019? Disponível em: < https://www.br.undp.org/content/brazil/pt/home/idh0/conceitos/o-que-edesenvolvimento-humano.html\#: :text=de $\% 20$ Desenvolvimento $\% 20$ Humano-

,O\%20que $\% 20 \%$ C3\%A9\%20Desenvolvimento $\% 20$ Humano, serem $\% 20$ aquilo $\% 20$ que $\%$ 20desejam $\% 20$ ser.\&text $=\mathrm{A} \% 20$ renda $\% 20 \% \mathrm{C} 3 \%$ A9\%20importante $\% 2 \mathrm{C} \% 20 \mathrm{mas}, \mathrm{e} \% 20$ n\%C3\%A3o\%20como\%20seu\%20fim.>. Acesso em: 19 abr. 2019.

PROMAR - FUNDAÇÃO PROMAR. Relatório do Macrodiagnóstico da Pesca Marítima do Estado do Espírito Santo. Relatório Técnico, FTM RT 005/05, Julho, 2005. Disponível em: <https://issuu.com/vozdanatureza/docs/namec65214>. Acesso em: 04 ago. 2019.

SIRVINSKAS, L. P. Manual de Direito Ambiental. São Paulo: Saraiva Educação, 2018.

SOS MATA ATLÂNTICA. Atlas dos Municípios: Aqui tem mata?. 2019?. Disponível em:

$<$ https://aquitemmata.org.br/\#/busca/es/Esp\%C3\%ADrito\%20Santo/Presidente\%20Ken nedy>. Acesso em: 18 abr. 2019.

THOMAZI, R. D.; ROCHA, R. T.; OLIVEIRA, M. V.; BRUNO, A. S.; SILVA, A. G. Um panorama da vegetação das restingas do Espírito Santo no contexto do litoral brasileiro. Natureza Online, v.11, n.1, p.1-6, 2013.

TRENNEPOHL, C.; TRENNEPOHL, T. Licenciamento Ambiental. São Paulo: Thomson Reuters Brasil, 2018.

VIEDERTTÉ, R.; DIKSAITÉ, L. Maritime clusters productivity and competiteveness evaluation methods: systematic approach. Megatrend revija - Megatrend Review, v. 11, n. 3, p. 215-228, 2014. 